\title{
Pre-Spud Mud Loss Flow Rate in Steeply Folded Structures
}

\author{
Zhiyuan Wang ${ }^{1 *}$, Baojiang Sun ${ }^{1}$ and $\mathrm{Ke} \mathrm{Ke}^{2}$ \\ ${ }^{1}$ School of Petroleum Engineering, China University of Petroleum (East China), Qingdao 266555 - China \\ ${ }^{2}$ SINOPEC Research Institute of Petroleum engineering, Beijing 100101 - China \\ e-mail: wangzy1209@126.com - sunbi1128@126.com - keke@sripe.cn \\ * Corresponding author
}

\begin{abstract}
Résumé - Prédiction du débit de perte des boues de démarrage dans des structures fortement plissées - Dans cet article, nous proposons une nouvelle méthode pour prédire le débit de perte de boues de démarrage avant forage de formations à fracturation tectonique dans des structures fortement plissées. Cette nouvelle méthode est basée sur la stimulation par éléments finis du champ de contraintes paléo-tectoniques et tectoniques, et de la répartition de la fracturation. Les étapes de la méthode sont les suivantes. Tout d'abord, la répartition des contraintes paléotectoniques est simulée par l'analyse par éléments finis. La répartition de la fracturation tectonique de la région est obtenue en combinant le critère de rupture des roches avec la distribution des contraintes paléo-tectoniques. Ensuite, les paramètres de rupture tels que la densité, l'ouverture, la porosité et la perméabilité des fractures tectoniques sont calculés en étudiant le processus de reconstruction de contraintes actuelles sur la fracturation tectonique. Enfin, le débit de perte des boues de démarrage est calculé en fonction des paramètres de rupture et des données de base pour un puits donné. La nouvelle méthode permet de prédire le débit de perte de boues de démarrage dans des structures fortement plissées.
\end{abstract}

\begin{abstract}
Pre-Spud Mud Loss Flow Rate in Steeply Folded Structures - In this paper, a new method that predicts the pre-spud mud loss flow rate in formations with tectonic fractures of steeply folded structures is proposed. The new method is based on finite element analysis of the palaeotectonic and current tectonic stress field and fracture distribution. The steps of the method are as follows. First, palaeo-tectonic stress distribution is simulated through finite element analysis. The tectonic fracture distribution of the region is obtained by combining rock failure criteria with palaeo-tectonic stress distribution. Afterward, the tectonic fracture density, aperture, porosity and permeability are calculated by studying the rebuilding process of current stress to the fracture parameters. Finally, the mud loss flow rate is calculated according to fracture parameters and the basic data of a given well. The new method enables the prediction of the mud loss flow rate before drilling steeply folded structures.
\end{abstract}




\section{INTRODUCTION}

Steeply folded structures have complex conditions and are prone to develop cracks, thereby leading to serious circulation loss during drilling and danger during the drilling process (Xu et al., 1997; Quintana et al., 2001; Du, 2004). Thus, predicting circulation loss during the pre-spud phase is important. Currently, numerous studies on methods predicting circulation loss concentrate on rock mechanics to describe and evaluate crustal stress (Prensky, 1992; Bell and Aadnøy, 1998; Desroches and Kurkjian, 1999; Nikolaevskiy and Economides, 2000), to analyze and investigate the tectonic fracture distribution, and to obtain pressure loss (Constant David and Bourgoyne, 1988; Rocha and Bourgoyne, 1996; Sadiq and Nashawi, 2000; Rocha et al., 2004). Determining the fracture pressure gradient from well $\operatorname{logs}$ is another way to predict circulation loss (Anderson et al., 1973; Holbrook, 1989; Draou and Osisanya, 2000). The methods mentioned above can predict whether circulation loss occurs or not. However, these methods cannot predict the mud loss flow rate before drilling, which is more important during the actual drilling process. Therefore, we propose a new method for predicting the mud loss flow rate in tectonic fractures of steeply folded structures. This new method is based on the numerical simulation of the tectonic stress field and fracture distribution (Dai and Li, 2000; Maerten and Maerten, 2006; Deng et al., 2006) and quantitative description of tectonic fracture parameters related to the mud loss flow rate, such as density, aperture, porosity and permeability (Murray, 1968; Chen and Bai, 1998; Ji et al., 2010a). The main steps of the method are as follows. The geological structure model is established according to the local tectonic fracture distribution and main tectonic movement period. Palaeo-tectonic stress distribution is calculated through finite element analysis, and tectonic fracture distribution of the region is calculated by combining rock failure criteria and palaeo-tectonic stress distribution. Another geological structure model for current stress simulation is established according to local current stress and tectonic features. Tectonic fracture density, aperture, porosity and permeability are calculated by studying the rebuilding process of current stress to the fracture parameters. Finally, the mud loss flow rate is calculated on the basis of fracture parameters and basic data, such as pore pressure profile, mud weight and fracture pressure, among others, in a given well. Taking Block F of a gas field in Sichuan Basin, China, as an example, the tectonic stress field and fracture distribution are analyzed. The predicted value of the mud loss flow rate agrees well with the actual value in Well PG-X1, which means that the method is feasible in predicting the mud loss flow rate before drilling steeply folded structures. This method will be helpful in applying preventive measures during the actual drilling practice in steeply folded structures.

\section{GEOLOGICAL STRUCTURE MODEL ESTABLISHMENT}

\subsection{Characteristic Analysis of Geological Structure}

The structure of the site, history of structural evolution, in situ basin structural characteristics, formation sequence and sediment fill were researched and analyzed by using tectonic evolution analysis to comprehend the characteristics of the geological structure (Wei Jia et al., 2008). The structural pattern, formation components, lithology and direction of the structure were determined. The depth of the layers of the structural diagram in the area was also obtained for model establishment.

\subsection{Geological Model Establishment}

By analyzing the geological structure characteristics, layers with similar lithology were grouped together. Geometry simplification was made by using the depth structural diagram, and the geological model of the area was established.

\section{FINITE ELEMENT ANALOGY OF TECTONIC STRESS DISTRIBUTION}

The numerical computations of stress distribution can be divided into two sections: palaeo-stress distribution and current stress distribution. As shown in Figure 1, the steps in the evaluation of palaeo-stress distribution are as follows. First, the historical period in which the fracture was formed and the shape of the geological structure pre- and after this period could be determined by using the results of the tectonic evolution analysis. A geological structure model can be established based on the shape of the geological structure before fracture formation. Afterward, the boundary conditions and loads are set by using the trial and error method, which is based on the deformation standard, until the geological structure gained by simulation agrees with the actual structure after fracture formation. Finally, palaeo-stress distribution can be determined by finite element analysis. The current stress distribution can be evaluated in the same way as the palaeo-stress distribution. However, the current geological structure, boundary conditions 


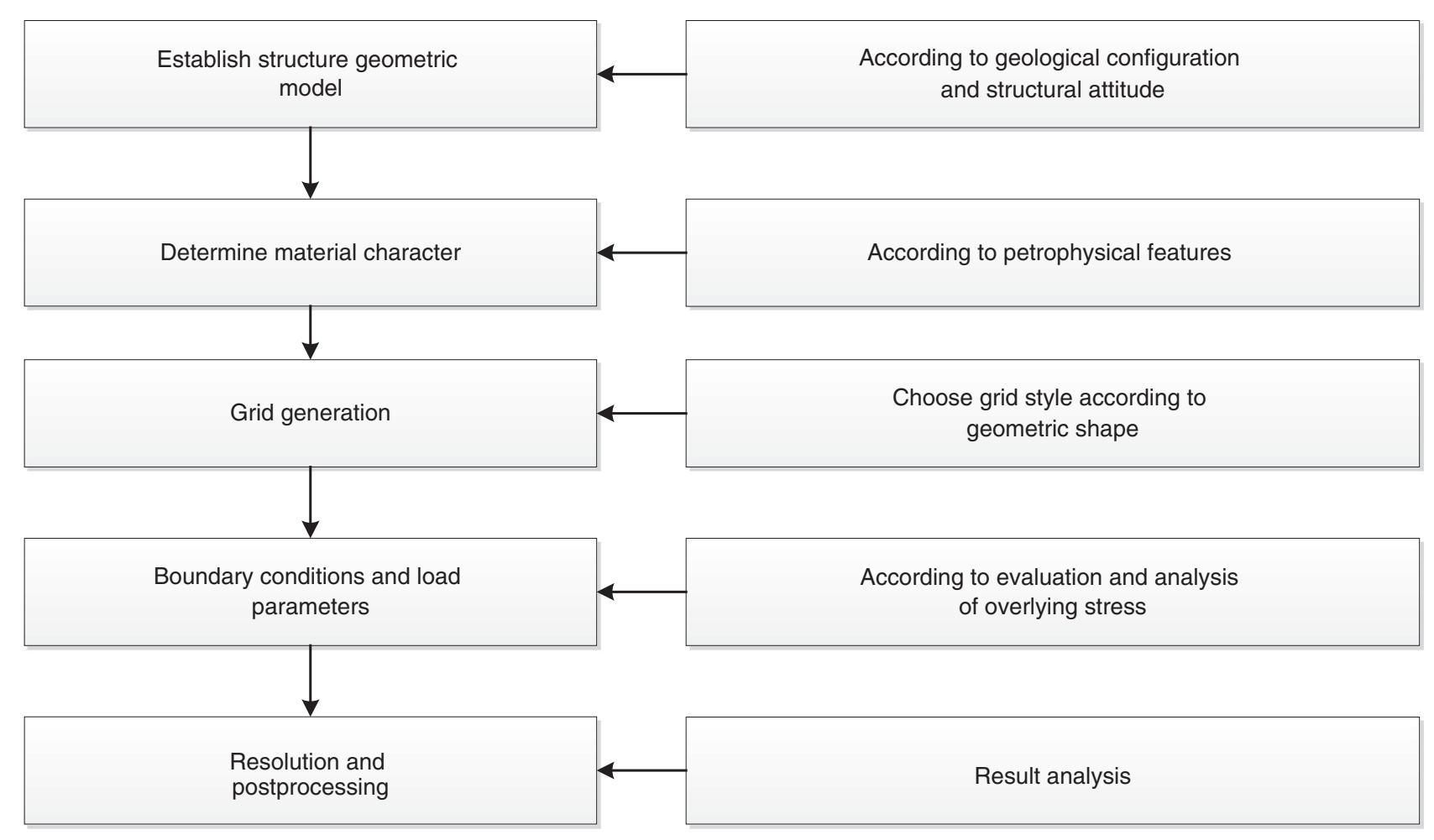

Figure 1

The flow diagram of tectonic fracture finite element analogy.

and loads are used during finite element analysis in the computation of current stress distribution. Current boundary loads can be determined through logging data, data of the indoor core experiment, data of hydraulic fracturing, and other kinds of well data in the area evaluated.

The constitutive law used in the simulation is a linear elastic model, which is commonly used in the fracture simulation process of pay zones (Coblentz and Sandiford, 1994; Kwon and Mitra, 2004).

\subsection{Boundary Conditions and Load Parameters of Palaeo-Tectonic Stress Simulation}

Accurately setting the factors influencing the control of the structural fracture is difficult because of the complexity of geological structure formation. Therefore, the boundary conditions and the load deformation of palaeo-tectonic stress simulation need repeated trial and error calculations. The deformation standard is applied in this paper. After the boundary conditions and load are loaded, the deformation of the geological body is matched with the practical characteristics. Simulation results are checked with the real structural features, particularly the shape, length and position of the anticlines, synclines or faults.

\subsection{Boundary Conditions and Load Parameters of Current Tectonic Stress Simulation}

Calculating the crustal stress in a drilled well is important in determining the boundary conditions and load parameters of the geological model for current tectonic stress simulation. Currently, numerous methods are available in evaluating crustal stress. The equations below are used for the evaluation of crustal stress in this paper (Gazaniol et al., 1995; Helio Santos et al., 1999; Ge et al., 2001). In this study, the fracturing method is used to calculate horizontal principal stress:

$$
\begin{gathered}
\sigma_{h}=p_{s} \\
\sigma_{H}=3 \sigma_{h}-p_{f}-p_{p}-S_{t}
\end{gathered}
$$

where $\sigma_{H}$ and $\sigma_{h}$ are the maximum and minimum horizontal principal stress, respectively (MPa); $p_{p}$ is the pore pressure $(\mathrm{MPa}) ; p_{s}$ is the instant knock-off pressure $(\mathrm{MPa}) ; p_{f}$ is fracture pressure (MPa); and $S_{t}$ is rock tensile strength (MPa). 
Hydraulic fracturing points are chosen as the key points of tectonic stress simulation based on the statistical hydraulic fracturing information of the wells drilled in the research area. The horizontal principal stress is obtained at the key points by using Equations (1), (2). Afterward, boundary conditions and load parameters are loaded using the trial and error method until the simulated tectonic stress is nearly consistent with the value calculated from the hydraulic fracturing in the key points. The differential value between simulated tectonic stress and calculated tectonic stress from hydraulic fracturing is less than $5 \%$ when few key points exist, whereas the differential value is larger than $5 \%$ when many key points exist.

\subsection{Procedure of Finite Element Analogy}

The procedure of finite element analogy is shown in Figure 1.

\section{QUANTITATIVE DESCRIPTIONS FOR TECTONIC FRACTURE PARAMETERS}

The parameters of tectonic fracture related to the prediction of the mud loss flow rate include fracture density, aperture, porosity and permeability. The current stress difference is low and cannot create new fractures. Current fracture density has the same value as palaeo-fracture density. Current stress can rebuild palaeo-fractures and can cause fracture aperture, porosity and permeability to change.

\subsection{Calculation Methods for Palaeo-Fracture Parameters}

\subsubsection{Fracture Density Calculation}

Rock deformation can accumulate strain energy under stress. Rock failure appears when the release rate of strain energy is equal to the energy required to form the fracture per unit area (surface energy density). Part of the strain energy released is utilized to provide energy for the increasing fracture surface area, and the remaining strain energy is released in the form of an elastic wave. The energy of the elastic wave is minimal and can be neglected.

The Coulomb-Mohr principle was applied in the examination of shear fracture under triaxial compression stress. The computation for fracture density under triaxial compression stress is as follows (Ji et al., 2010b):

$$
\begin{gathered}
\text { see equation (3) below } \\
D_{l f}=\frac{2 D_{v f_{c}} L_{1} L_{3} \sin \theta \cos \theta-L_{1} \sin \theta-L_{3} \cos \theta}{L_{1}^{2} \sin ^{2} \theta+L_{3}^{2} \cos ^{2} \theta} \\
\theta=45^{\circ}-\frac{\varphi}{2}
\end{gathered}
$$

The Griffith-failure principle was applied in the examination of tension fracture under tension stress. When $\left(\sigma_{1}+3 \sigma_{3}\right)>0$, then the formula for fracture density under tensile stress is as follows:

$$
\begin{gathered}
D_{\mathrm{Vf}}=\frac{\left(\sigma_{1}^{2}+\sigma_{2}^{2}+\sigma_{3}^{2}-2 \mu\left(\sigma_{1} \sigma_{2}+\sigma_{2} \sigma_{3}+\sigma_{1} \sigma_{3}\right)-\sigma_{t}^{2}\right)}{2 E J} \\
D_{l f}=\frac{2 D_{v f} L_{1} L_{3} \sin \theta \cos \theta-L_{1} \sin \theta-L_{3} \cos \theta}{L_{1}^{2} \sin ^{2} \theta+L_{3}^{2} \cos ^{2} \theta} \\
\theta=\frac{1}{2} \arccos \left(\frac{\sigma_{1}-\sigma_{3}}{2 \sigma_{1}+2 \sigma_{3}}\right)
\end{gathered}
$$

Let $\left(\sigma_{1}+3 \sigma_{3}\right) \leq 0, \sigma_{3}=-\sigma_{t}$ and $\theta=0$. Thus, when $\theta$ is equal to zero, the fracture plane is parallel to the direction of $\sigma_{1}$ and perpendicular to the direction of $\sigma_{3}$, so the fracture linear density equals the total number of fractures in the rock volume. The formula for fracture density is as follows:

$$
D_{l f}=D_{v f} \quad \theta=0
$$

where $D_{\mathrm{Vf}_{c}}$ is the fracture volume density under triaxial compression stress $\left(\mathrm{m}^{-2}\right) ; D_{\mathrm{Vf}}$ is the fracture volume density under tensile stress $\left(\mathrm{m}^{-2}\right)$; $D_{\text {lf }}$ is the fracture linear density $\left(\mathrm{m}^{-1}\right) ; \sigma_{1}, \sigma_{2}$ and $\sigma_{3}$ are the maximum principal stress, the intermediate principal stress and the minimum principal stress $(\mathrm{Pa}) ; E$ is the elastic modulus (Pa); $\mu$ is the Poisson ratio; $L_{1}$ and $L_{3}$, respectively, are the side length along the maximum principal stress direction and the minimum principal stress direction of the represent element volume $(\mathrm{m}) ; \sigma_{\mathrm{d}}$ is the uniaxial compression stress when macro-fractures are going to appear, which can be confirmed by experiment $(\mathrm{Pa})$; $J$ is the surface energy density of fractures $\left(\mathrm{J} / \mathrm{m}^{2}\right) ; \theta$ is the rupture angle (the angle between the maximum principal stress direction and the fracture orientation) $\left({ }^{\circ}\right)$; and $\varphi$ is the angle of internal friction $\left(^{\circ}\right)$.

$$
D_{\mathrm{Vf}_{c}}=\frac{\left(\sigma_{1}^{2}+\sigma_{2}^{2}+\sigma_{3}^{2}-2 \mu\left(\sigma_{1} \sigma_{2}+\sigma_{2} \sigma_{3}+\sigma_{1} \sigma_{3}\right)-\sigma_{d}^{2}+2 \mu\left(\sigma_{2}+\sigma_{3}\right) \sigma_{d}\right)}{2 E J}
$$




\subsubsection{Fracture Aperture Calculation}

The formula of fracture aperture $b$ is as follows (Hicks et al., 1996):

$$
b=\frac{\varepsilon_{f}}{D_{l f}}=\frac{|\varepsilon|-\left|\varepsilon_{0}\right|}{D_{l f}}
$$

where $\varepsilon$ is the tension strain of the rock cell cube under current stress conditions and $\varepsilon_{0}$ is the greatest tension strain of rock elastic deformation.

\subsubsection{Fracture Porosity Calculation}

Fracture porosity is the ratio of total fracture volume and total rock volume. For a single population fracture, the relationship between fracture porosity and fracture volume density and aperture is as follows (Chen and Bai, 1998):

$$
\phi_{f}=b D_{v f}
$$

where $\phi_{f}$ is the fracture porosity (\%).

For multi-bank fractures, fracture porosity is calculated as follows:

$$
\phi_{f t}=\sum_{i}^{m} b_{i} D_{v f i}
$$

where $\phi_{f t}$ is the fracture total porosity $(\%) ; m$ is the group number of fractures; and $b_{i}$ is the aperture of the $i$ th group fracture $(\mathrm{m})$.

\subsubsection{Fracture Permeability Calculation}

Fluid flow in a unitary fracture is mainly confined to a two-dimensional crack plane, and the penetration perpendicular to the crack plane can be neglected. Hence, a faceplate filtration model can be applied when calculating fracture permeability (Song et al., 1999):

$$
\left[\begin{array}{c}
K_{f x} \\
K_{f y} \\
K_{f z}
\end{array}\right]=\sum_{i}^{m}\left[\begin{array}{c}
K_{f x i} \\
K_{f y i} \\
K_{f z i}
\end{array}\right]=\sum_{i}^{m} \frac{b_{i}^{3} D_{l f i}}{12}\left[\begin{array}{c}
\cos ^{2} \theta_{i} \\
1 \\
\sin ^{2} \theta_{i}
\end{array}\right]
$$

where $K_{f x}, K_{f y}$ and $K_{f z}$, respectively, are the fracture permeability along $\sigma_{1}, \sigma_{2}$ and $\sigma_{3}$ directions when multi-bank fractures exist $\left(10^{-3} \mu \mathrm{m}^{2}\right)$, and $\theta_{i}$ is the rupture angle of the $i$ th group fracture.

\subsection{Calculation Methods for Current Fracture Parameters}

Hicks et al. (1996) proposed Equation (14) to calculate fracture aperture in consideration of the influence of normal stress and shear stress on fracture aperture:

$$
b_{m}=\frac{b_{0}}{1+9 \sigma^{\prime} / \sigma_{\text {nref }}}+\Delta b_{s}+b_{c}
$$

where $b_{\mathrm{m}}$ is the current fracture aperture $(\mathrm{m}) ; b_{0}$ is the initial fracture aperture (m); $\sigma_{\text {nref }}$ is the effective normal stress (MPa); $\sigma^{\prime}$ is the effective normal stress when fracture aperture decreases $90 \%(\mathrm{MPa}) ; b_{0}$ is the aperture increment due to shear displacement $(\mathrm{m}) ; b_{s}$ is the fracture aperture which is superficial under maximum normal stress (m).

Minimal shear displacement occurred in the current formation. Thus, $b_{c}$ usually has a low value and can be neglected; the initial fracture aperture can be considered as palaeo-fracture aperture $b ; \sigma^{\prime}$ is equal to the pressure difference on fractures between normal stress and formation fluid pressure. Thus, Equation (14) transforms into Equation (15):

$$
b_{m}=\frac{b_{0}}{1+9 \sigma_{n} / \sigma_{\text {nref }}}
$$

where $\sigma_{\mathrm{n}}$ is the normal stress on fractures (MPa).

The calculation methods for current fracture parameters can be obtained by replacing fracture aperture $b$ in Equations (10) and (11) with current fracture aperture.

\section{CALCULATION OF MUD LOSS FLOW RATE}

As shown in Figure 2, the flow path of mud can be divided into three parts based on the flow behavior of drilling fluid in fissured formation: flow in a fracture, flow in mud cake, and flow in formation.

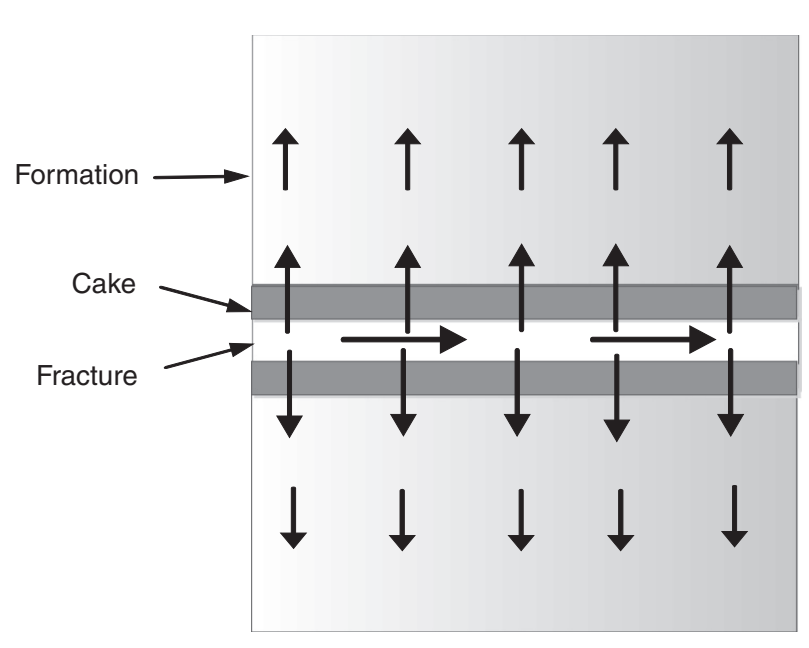

Figure 2

The schematic diagram of mud loss in a fracture, cake and formation. 


\subsection{Fracture Flow}

Equations (16), (17) and (18) can be used to describe the flow behavior of the drilling fluid loss in the fracture if the fractures are supposed to be horizontal. Lavrov and Tronvoll (2004) deduced an equation describing the flow of a power-law fluid from a borehole into a deformable fracture of finite extension:

$$
\begin{gathered}
\frac{\partial b}{\partial t}-\frac{n b^{(2 n+1) / n}}{(2 n+1) 2^{(n+1) / n} K_{c i}^{1 / n}} \frac{1}{r} \frac{\partial p}{\partial r}\left|\frac{\partial p}{\partial r}\right|^{(1-n) / n} \\
-\frac{n}{(2 n+1) 2^{(n+1) / n} K_{c i}^{1 / n}} \frac{\partial}{\partial r}\left[b^{(2 n+1) / n} \frac{\partial p}{\partial r}\left|\frac{\partial p}{\partial r}\right|^{(1-n) / n}\right]=0 \\
\frac{\partial b}{\partial t}=\frac{1}{K_{n}} \frac{\partial p}{\partial t}
\end{gathered}
$$

The mud loss flow rate is evaluated by the following:

$$
u=-\frac{2 \pi r_{w} n b^{(2 n+1) / n}}{(2 n+1) 2^{(n+1) / n} K_{c i}{ }^{1 / n}} \frac{\partial p}{\partial r}\left|\frac{\partial p}{\partial r}\right|^{(1-n) / n}
$$

where $b$ is fracture aperture $(\mathrm{m}) ; t$ is the time (s); $n$ is the power-law exponent; $K_{c i}$ is the consistency index $\left(\mathrm{Pa} \cdot \mathrm{s}^{\mathrm{n}}\right) ; K_{n}$ is the normal fracture stiffness $(\mathrm{Pa} / \mathrm{m}) ; p$ is the pressure inside the fracture $(\mathrm{Pa}) ; r$ is the distance from the borehole axis in the fracture plane $(\mathrm{m}) ; r_{w}$ is the wellbore radius (m); and $u$ is the mud loss flow velocity $(\mathrm{m} / \mathrm{s})$.

\subsection{Formation Flow}

Equations (19-21) can be used to describe the flow behavior of the drilling fluid loss in formation. Equation (19) is the Darcy flow equation:

$$
\nabla\left(\rho \frac{K_{d}}{\mu_{e}} \nabla p\right)=C_{t} \phi_{d} \frac{\partial p}{\partial t}
$$

The effective viscosity of drilling fluid changes with the rate of shearing is expressed as follows (Williams, 1990):

$$
\mu_{e}=\frac{1}{\alpha_{u}} \cdot \frac{3 n+1}{8 n}\left(\frac{\phi_{d}}{8 K_{d}}\right)^{\frac{1-n}{2 n}}\left(2 K_{c i}\right)^{\frac{1}{n}}\left(-\frac{\partial p}{\partial r}\right)^{\frac{n-1}{n}}
$$

The relationship between the flow velocity and the pressure difference can be described as Equation (21) in porous media (Settari, 1988).

$$
u=\frac{\phi n}{3 n+1}\left(\frac{8 K_{d}}{\phi_{d}}\right)^{\frac{1-n}{2 n}}\left(2 K_{c i}\right)^{\frac{1}{n}}\left(\frac{\partial p}{\partial r}\right)^{\frac{1}{n}}
$$

where $\phi$ is the pressure inside the formation $(\mathrm{Pa}) ; \rho$ is the drilling fluid density $(\mathrm{kg} / \mathrm{m}) ; \phi_{d}$ is the formation porosity $(\%) ; K_{d}$ is the formation permeability $\left(\mu \mathrm{m}^{2}\right) ; C_{t}$ is the formation compressibility coefficient $\left(\mathrm{Pa}^{-1}\right) ; \alpha_{u}$ is the unit conversion coefficient; and $\mu_{e}$ is the effective viscosity of the drilling fluid.

\subsection{Cake Flow}

Equations (22-24) can be used to describe the flow behavior of the drilling fluid loss in the mud cake. The mud cake is considered a porous medium with the porosity $\phi_{C}$ and the permeability $K_{C}$. Equation (22) is the flow equation in mud cake (Warpinski, 1991):

$$
\nabla\left(\rho \frac{K_{c}}{\mu_{e}} \nabla p\right)=C_{c} \phi_{c} \frac{\partial p}{\partial t}
$$

The effective viscosity of drilling fluid in the mud cake is expressed as follows:

$$
\mu_{e}=\frac{1}{\alpha_{u}} \cdot \frac{3 n+1}{8 n}\left(\frac{\phi_{C}}{8 K_{C}}\right)^{\frac{1-n}{2 n}}\left(2 K_{c i}\right)^{\frac{1}{n}}\left(-\frac{\partial p}{\partial r}\right)^{\frac{n-1}{n}}
$$

The relationship between flow velocity and pressure difference can be described as Equation (24) in mud cake (Vitthal and McGowen, 1996).

$$
u^{n}=\frac{\alpha_{u}^{n}}{32 K_{c i}}\left(\frac{\phi_{C} n}{3 n+1}\right)^{n}\left(\frac{8 K_{C}}{\phi_{C}}\right)^{\frac{n+1}{2}} \frac{p_{f}-p_{w}}{L}
$$

where $\phi_{c}$ is the mud cake porosity $(\%) ; K_{c}$ is the mud cake permeability $\left(\mu \mathrm{m}^{2}\right) ; C_{c}$ is the mud cake compressibility coefficient $\left(\mathrm{Pa}^{-1}\right) ; p_{f}$ is the formation pressure (Pa); $p_{w}$ is the bottom hole flowing pressure $\left(\mathrm{Pa}^{-1}\right)$; and $L$ is the drilling fluid flow distance (m).

Two main types of drilling fluid loss commonly exist in the fracture formation: loss due to hydraulic fracturing and loss due to pressure difference. When the annular pressure is higher than fracture pressure, the formation will form major fractures and loss due to fracturing will occur. Formation permeability is usually high in steeply folded structures. Thus, the loss due to pressure difference tends to exist when annular pressure is higher than pore pressure. The flow rate of loss due to fracturing can be calculated by using Equations (16-24). The flow rate of loss due to over-pressure can be calculated by using Equations (19-24). However, the mud cake is formed in the borehole wall instead of in the fracture surface. Permeability and porosity are calculated by using the quantitative description method for tectonic fracture parameters mentioned above. 


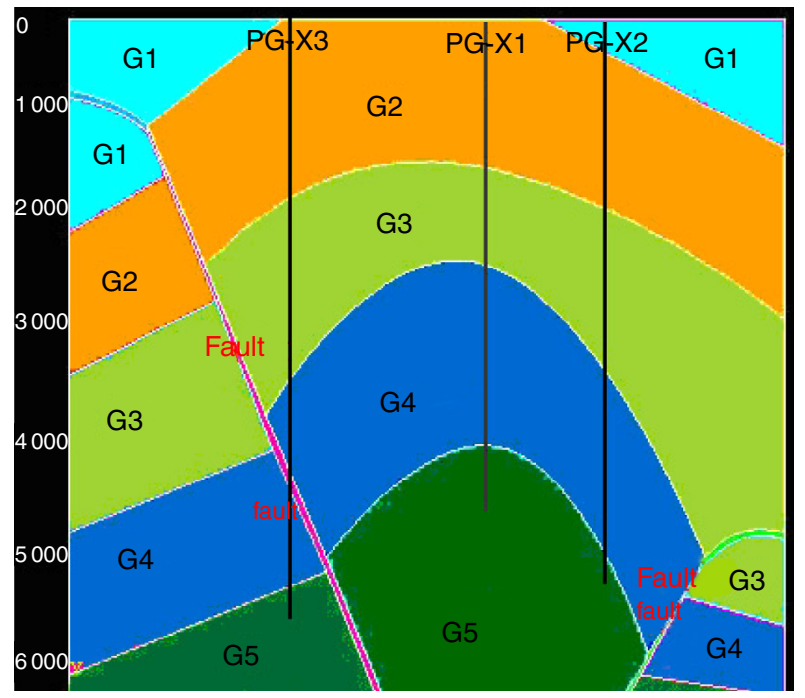

Figure 3

Structural profile of Block F.

\section{CASE STUDIES ON QUANTITATIVE DESCRIPTION OF TECTONIC FRACTURE AND MUD LOSS FLOW RATE}

Figure 3 is a simplified structure profile diagram of Block F of a gas field in Sichuan Basin, China. Structure formations can be divided into five groups, namely, G1, G2, G3, G4 and G5. G4 has had the highest drilling fluid loss in the drilling process; thus, G4 is taken as an example in the finite element analysis of palaeo-stress and current stress and in the quantitative description of tectonic fracture. Figure 4 shows the depth structure of G4. The parameter values of the materials used in the model are listed in Table 1.

The load value and azimuth of palaeo-stress simulation are as follows. The palaeo-maximum principal stress is considered in the EW direction, according to local fracture development. The maximum and minimum principal stress values are $296 \mathrm{MPa}$ and $165 \mathrm{MPa}$, respectively. These stress values are obtained by trial and error calculation until the deformation agrees with the actual shape characteristic of the geological structure.

The load value and azimuth of current stress simulation are as follows. According to the results of the measured local stress, the current stress azimuth is between NE $76^{\circ}$ and $\mathrm{NE} 88^{\circ}$, and the mean value is $83^{\circ}$. Thus, the angle between the current stress azimuth and the structure alignment direction is small. Moreover, the model profile bears extrusion force, which is mainly caused by the stress in the EW direction and gravity. According to the stress value of the key points and trial and error calculation, the

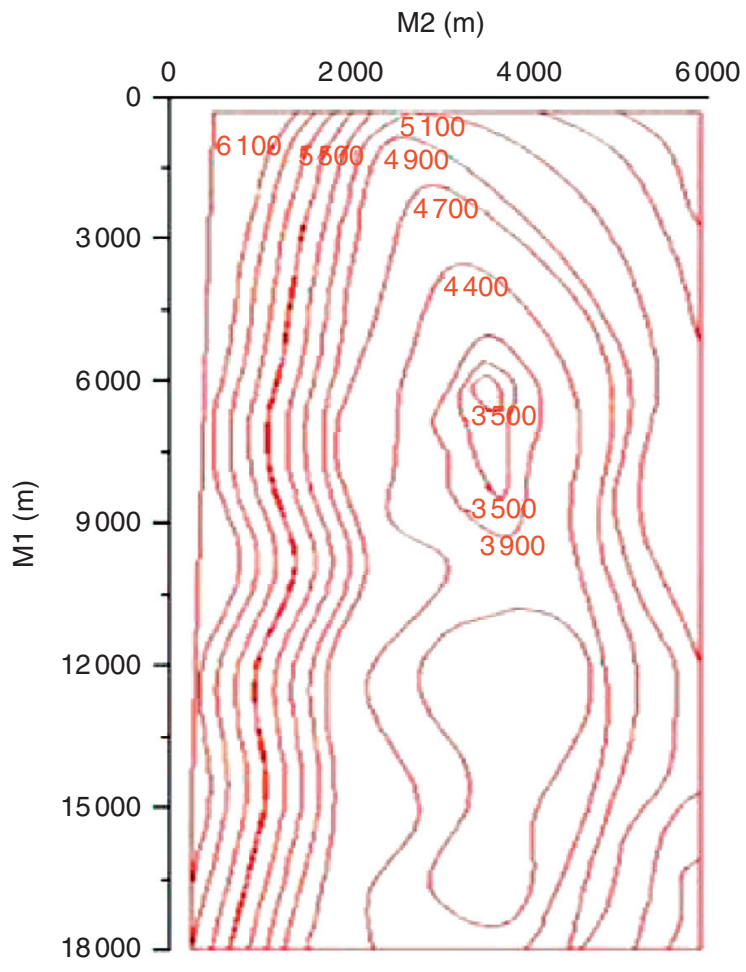

Figure 4

G4 depth structure of Block F.

TABLE 1

Parameters of model materials

\begin{tabular}{c|c|c|c}
\hline $\begin{array}{c}\text { Group } \\
\text { name }\end{array}$ & $\begin{array}{c}\text { Volume weight } \\
\left(\mathrm{kN} / \mathrm{m}^{3}\right)\end{array}$ & $\begin{array}{c}\text { Young's } \\
\text { modulus (GPa) }\end{array}$ & $\begin{array}{c}\text { Poisson } \\
\text { ratio }\end{array}$ \\
\hline L1 & 20 & 5 & 0.40 \\
\hline L2 & 21 & 25 & 0.30 \\
\hline L3 & 22 & 30 & 0.28 \\
\hline L4 & 24 & 40 & 0.25 \\
\hline L5 & 26 & 47 & 0.24 \\
\hline
\end{tabular}

maximum and minimum principal stress values are $123 \mathrm{MPa}$ and $90.2 \mathrm{MPa}$, respectively.

\subsection{Results of Tectonic Stress and Fracture Simulation}

Tectonic fracture density distribution is calculated by using the results of the palaeo-stress simulation and by using the Coulomb-Mohr criterion and Griffithfailure criterion as criteria of shear failure and tension failure, respectively. Tectonic fracture density, 
aperture, porosity and permeability are determined by simulating the rebuilding process of current stress to the fracture parameters on the basis of the results of the palaeo-stress simulation. Figures 5-8 show the results of tectonic fracture density, aperture, porosity and permeability.
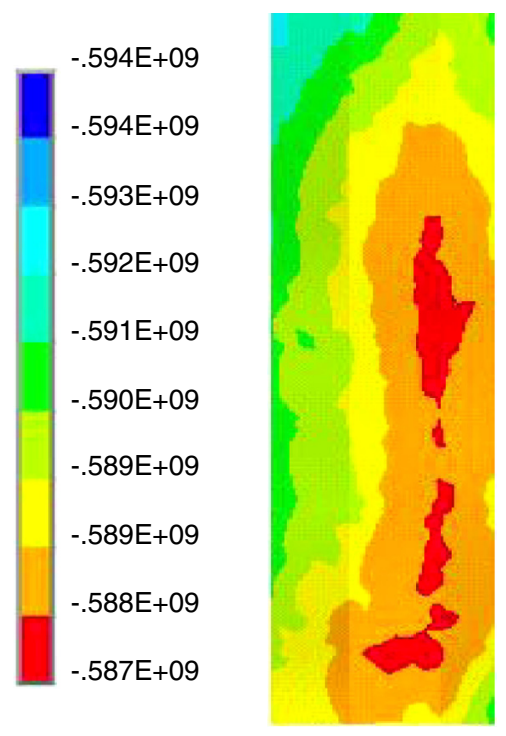

Greatest principal stress (Pa)
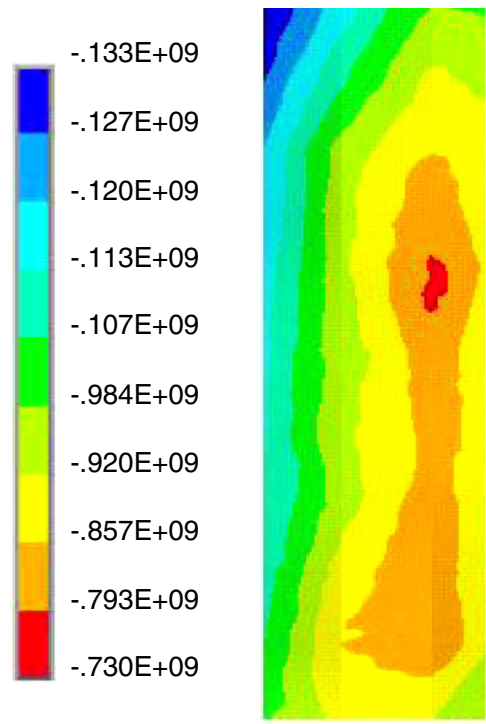

Least principal stress $(\mathrm{Pa})$
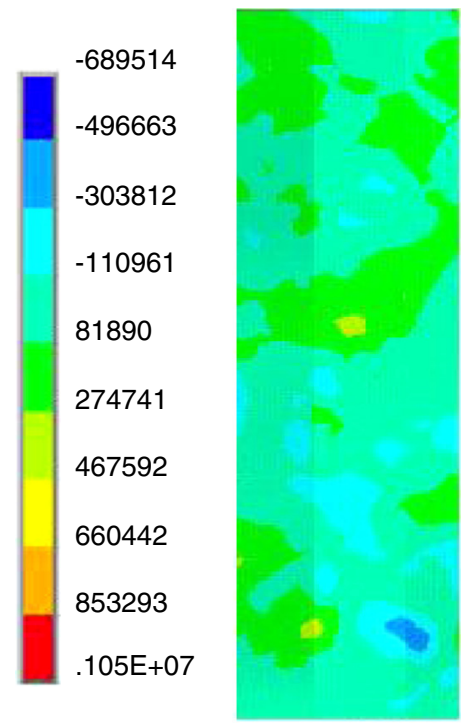

Shearing stress $(\mathrm{Pa})$

Figure 5

Tectonic fracture stress distribution of G4 in Block F.

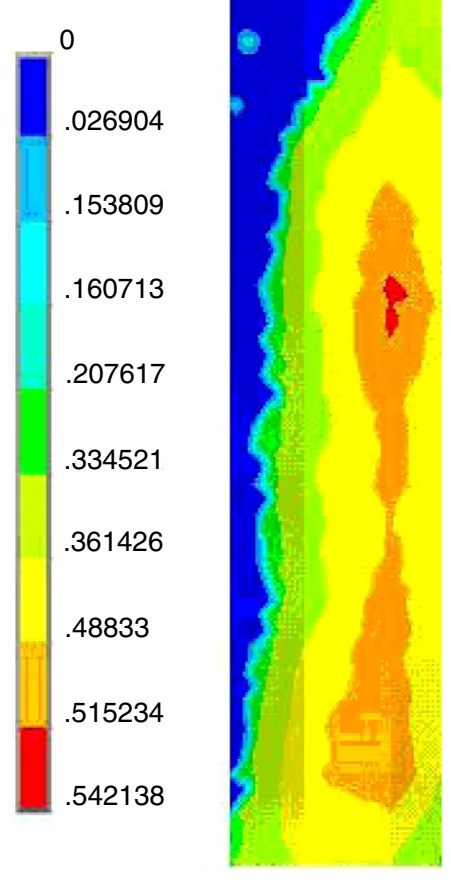

Latitudinal $(\mathrm{mm})$

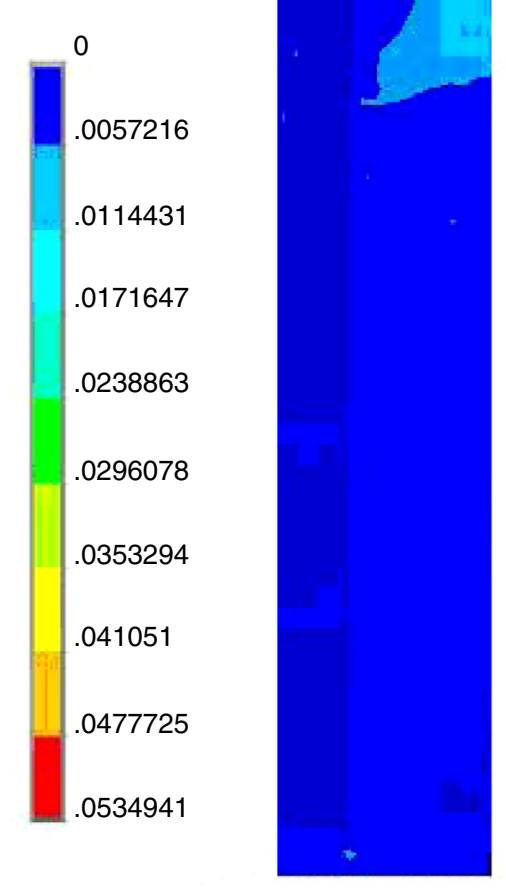

Longitudinal ( $\mathrm{mm})$

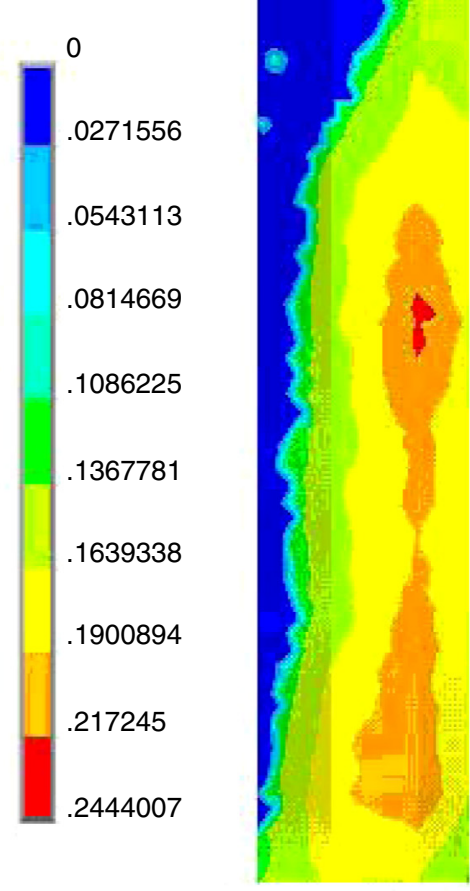

Total $(\mathrm{mm})$

Figure 6

Tectonic fracture aperture distribution of G4 in Block F. 


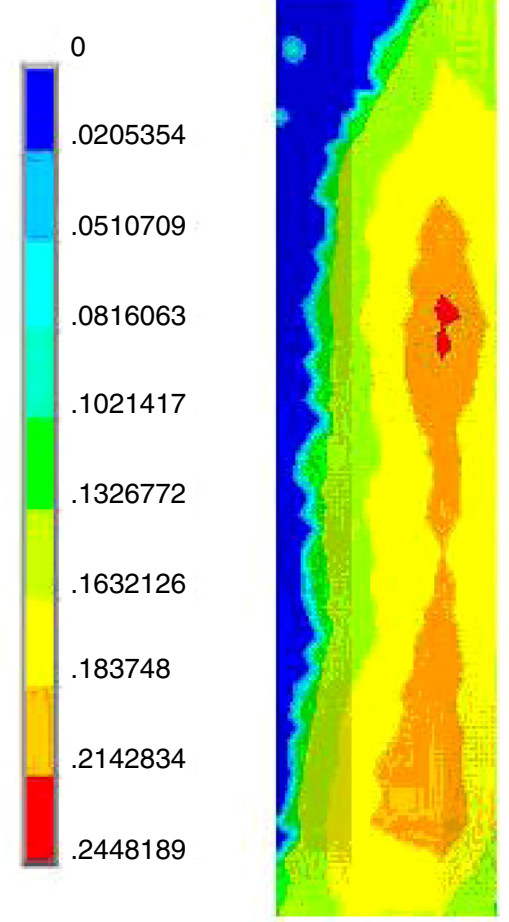

Porosity (\%)

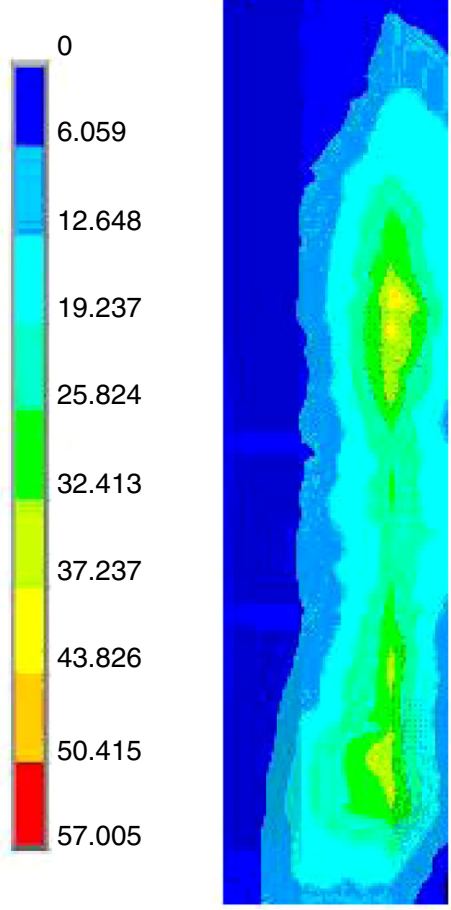

Latitudinal permeability $\left(10^{-3 \mu m^{2}}\right)$

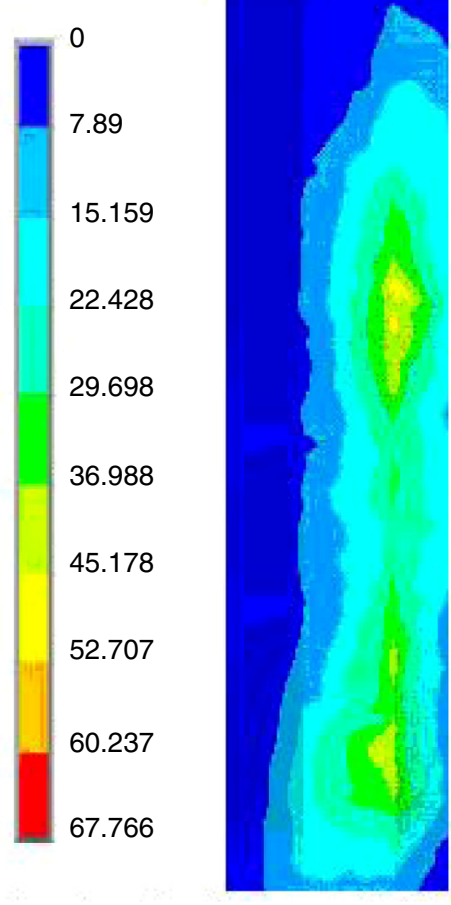

Longitudinal permeability $\left(10^{-3 \mu m^{2}}\right)$

Figure 7

Tectonic fracture porosity and permeability distribution of G4 in Block F.

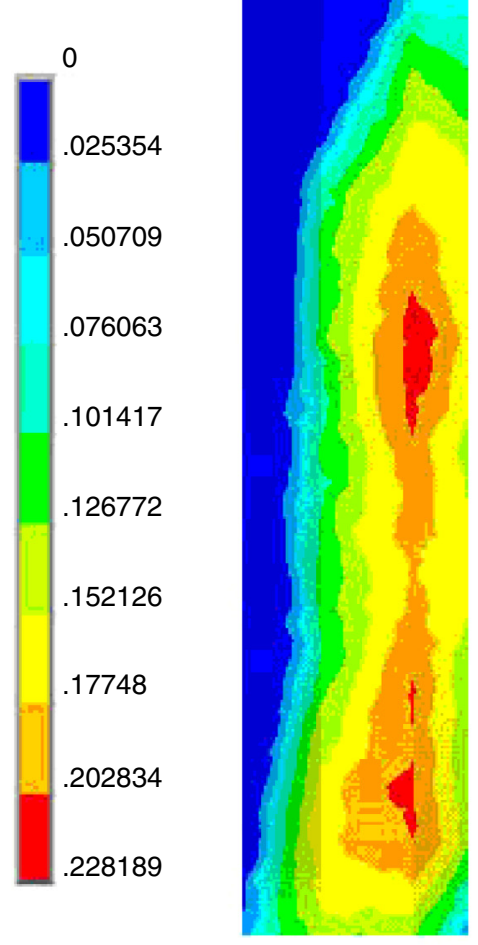

Latitudinal $\left(\mathrm{m}^{-1}\right)$

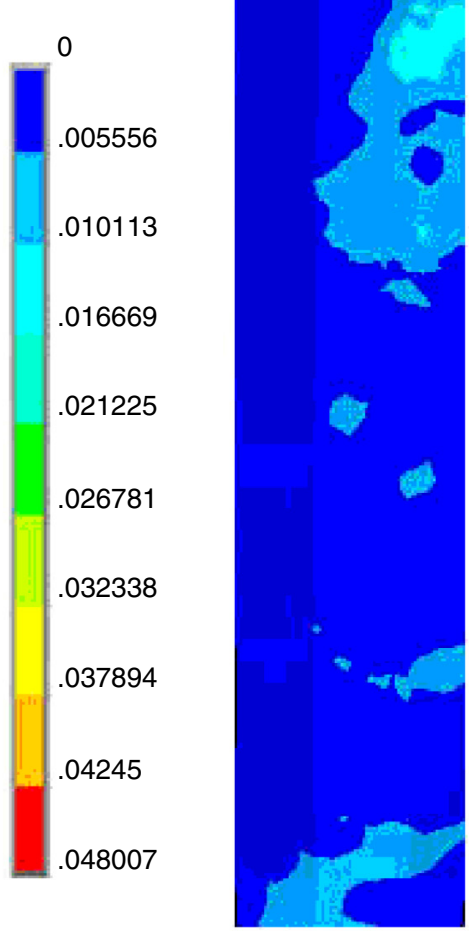

Longitudinal $\left(\mathrm{m}^{-1}\right)$
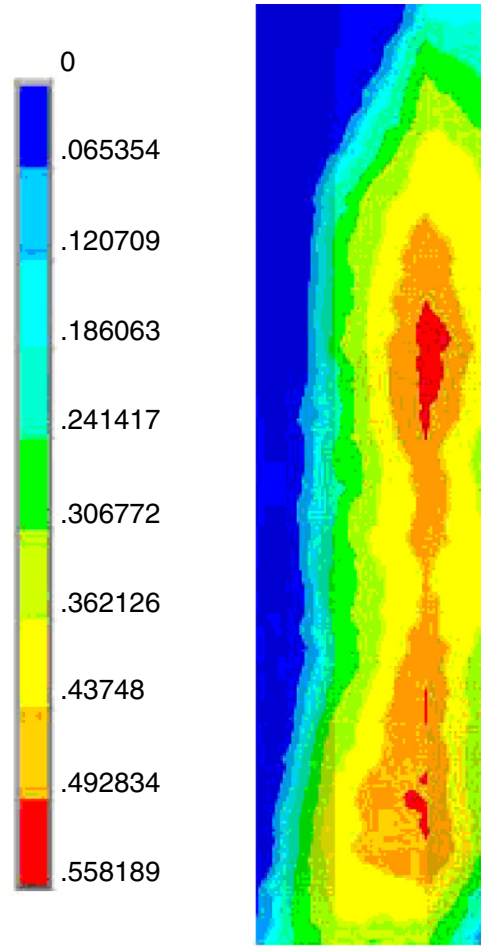

Total $\left(\mathrm{m}^{-1}\right)$

Figure 8

Tectonic fracture linear density distribution of G4 in Block F. 
According to the stress distribution shown in Figure 5, the stress at the top of the anticline or fold is greater than the other areas of the anticline. A stress concentration phenomenon exists in the top area. The stress on the top region is stronger than the other areas, and the destructive effects of rock in this region are stronger than the other areas.

Figure 6 displays the tectonic fracture aperture distribution of G4 in Block F. The tectonic fracture aperture in the core of the fold or at the top of the structure is apparently greater compared with other zones. The maximum predictive value is up to $0.5 \mathrm{~mm}$, and serious leakage will probably occur when drilling at this zone. The calculation of the fracture aperture not only contributes to mud loss prediction but also helps in the selection of the type and size of bridging material.

Figure 7 reveals the tectonic fracture porosity and permeability distribution of G4 in Block F. The distribution of porosity and permeability is highly inconsistent with that of the fracture aperture. The area with high porosity and permeability also has a large aperture. The porosity at the top reaches up to $0.25 \%$, and the permeability reaches up to $50 \times 10^{-3} \mu \mathrm{m}^{2}$.

Figure 8 shows the fracture linear density distribution. Similarly to Figure 5, the density of the tectonic fracture at the top is greater compared with the other zones in the steeply folded structure. The maximum value is up to $0.55 \mathrm{~m}^{-1}$ or even higher.

The distribution of key fracture parameters of G4 in Block $\mathrm{F}$ is determined by using the above analysis. The key fracture parameters at different positions of the whole structure can be obtained by utilizing the same method and finite element analysis applied in G4 in G1, G2, G3 and G5.

\subsection{Results of Mud Loss Flow Rate Simulation}

Predicting the mud loss flow rate at the different positions of the steeply folded structure can be carried out based on the calculation of fracture aperture, porosity, permeability and density, and by applying fluid flow mechanics. Well PG-X1 had serious mud loss, and its location is marked as "Well PG-X1" in Figure 3. Figure 9 shows the equivalent density profiles of pore pressure, fracture pressure and overburden pressure, as well as the drilling fluid density profile of Well PG-X1. Mud is a power-law fluid, with $n$ equal to 0.75 and $K_{c i}$ equal to $0.03 \mathrm{~Pa} \cdot \mathrm{s}^{0.75}$. The main part of the drill string is the $127-\mathrm{mm}$ drill pipe. Table 2 illustrates the well structure of Well PG-X1.

As shown in Figure 10, the mud loss flow rate of Well PG-X1 was predicted by using the proposed method. Severe mud loss occurred when drilling at the bottom

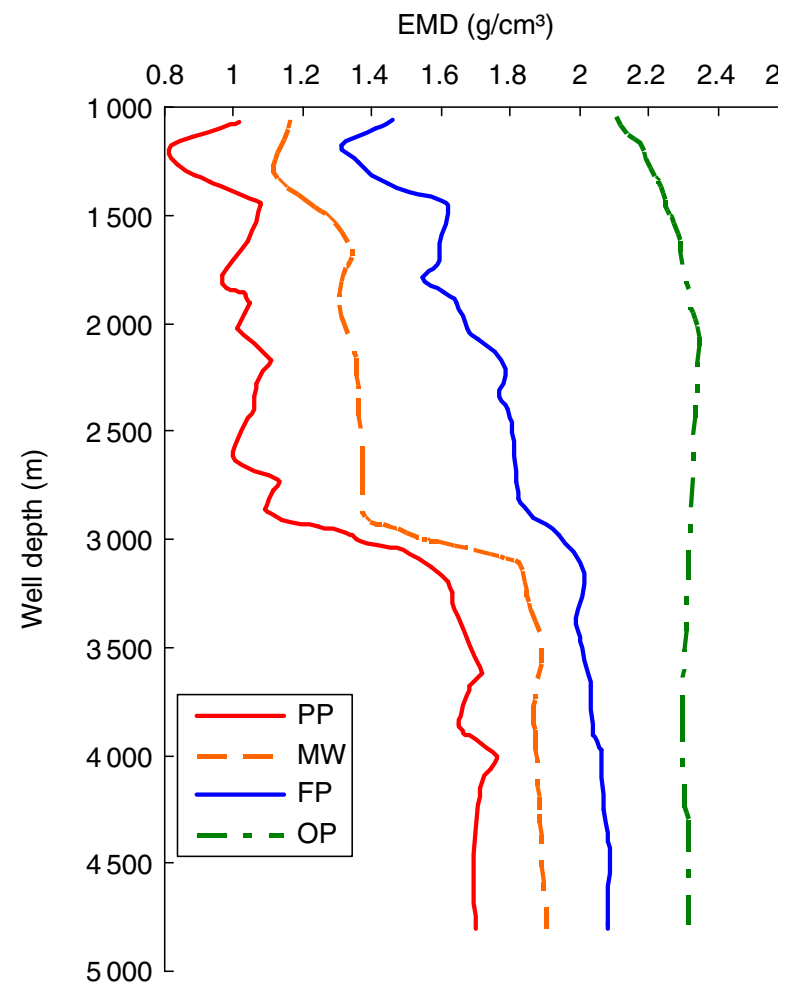

Figure 9

Pore Pressure (PP), Fracture Pressure (FP), Overburden Pressure (OP) and Mud Weight (MW) of Well PG-X1.

TABLE 2

PG-X1 well structure

\begin{tabular}{c|c|c|c}
\hline $\begin{array}{c}\text { Well depth } \\
(\mathrm{m})\end{array}$ & $\begin{array}{c}\text { Bit size } \\
(\mathrm{mm})\end{array}$ & $\begin{array}{c}\text { Casing size } \\
(\mathrm{mm})\end{array}$ & $\begin{array}{c}\text { Casing setting } \\
\text { depth }(\mathrm{m})\end{array}$ \\
\hline 540 & 660.4 & 508.0 & 538 \\
\hline 2316 & 444.5 & 339.7 & 2314 \\
\hline 3932 & 311.1 & 244.5 & 3930 \\
\hline 4857 & 215.9 & 177.8 & 4855 \\
\hline
\end{tabular}

of $\mathrm{G} 2$ and at most parts of G4. The average mud loss flow rate reached $64 \mathrm{~m}^{3} / \mathrm{h}$, and the total loss volume was approximately $560 \mathrm{~m}^{3}$ in G4. The predictive value of the mud loss flow rate agrees well with the actual value shown in Figure 10, which verifies the feasibility of the proposed method in predicting the mud loss flow rate.

Two other wells will be drilled in the structure and are marked as "PG-X2" and "PG-X3", as shown in Figure 3. Figure 11 displays the profiles of the mud loss flow rate in Well PG-X2 and Well PG-X3, which are based on the 


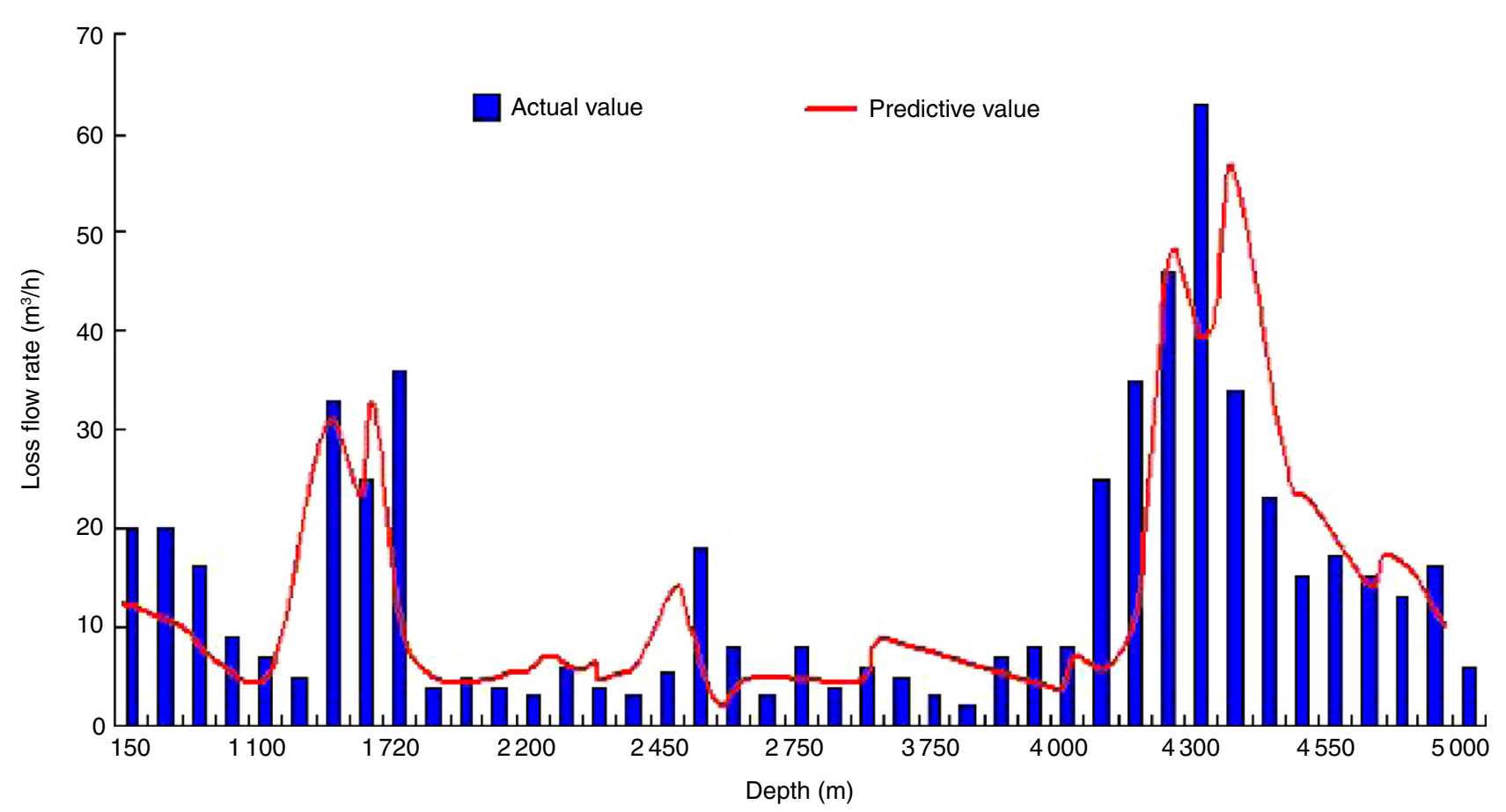

Figure 10

Actual value and predictive value of mud loss flow rate in Well PG-X1.

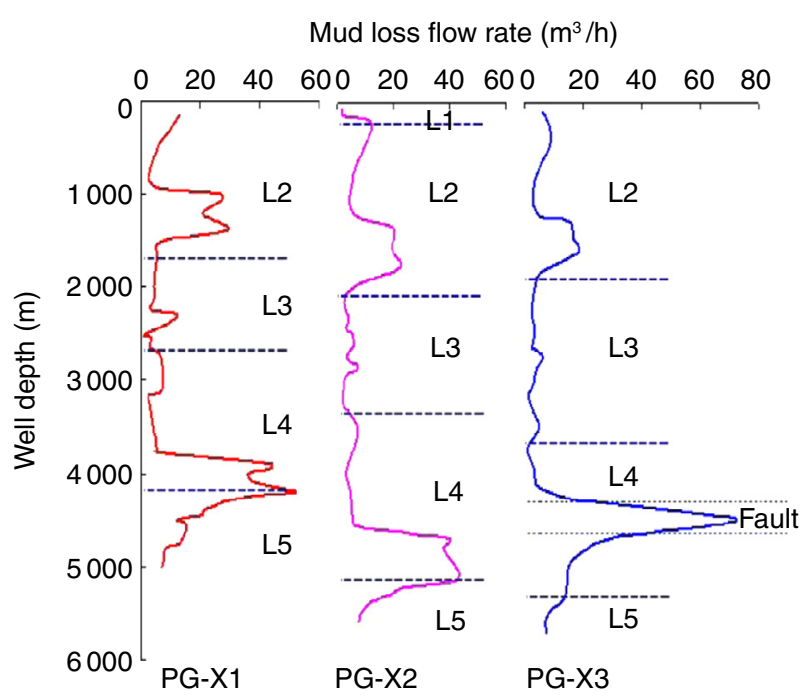

Figure 11

Predictive value of mud loss flow rate in Well PG-X1, Well PG-X2 and Well PG-X3.

results of crustal stress and tectonic fracture distribution simulation. The bottom parts of G2 and G4 have the highest mud loss flow rate in Well PG-X2, which is similar in Well PG-X1. Consequently, the middle part of G4 (4 $400 \mathrm{~m}$ to $4600 \mathrm{~m}$ ), at which the fault crosses the formation, has the highest mud loss flow rate in Well PG-X3. Overall, the mud loss flow rate of Well PG-X1 is higher than those of Well PG-X2 and Well PG-X3. The mud loss flow rate of most parts of Well PG-X3 is low, except for the fault parts where serious cracks have developed. The positions with more serious mud loss lie in the core of the structure, whereas those in the flank of the structure have less mud loss, which is in accordance with the fracture distribution of the structure.

\section{CONCLUSION}

By integrating the theory of geological mechanics, rock mechanics and fluid mechanics, we proposed a new method to predict the mud loss flow rate before drilling the tectonic fracture of steeply folded structures. The steps of predicting the mud loss flow rate are as follows: geological structure model establishment, finite element analysis, quantitative calculation of tectonic fracture parameters, and mud loss flow rate prediction. Quantitative description of tectonic fracture parameters related to the mud loss flow rate, such as density, aperture, porosity and permeability, plays an important role in 
predicting the mud loss flow rate. The density, aperture, porosity and permeability of tectonic fractures at the top of the structure are greater than those of the other zones. The predicted value of the mud loss flow rate agrees well with the actual value in Well PG-X1, which means that the method is feasible in predicting the mud loss flow rate before drilling. The wells have more serious mud loss in the core of the structure, and the wells in the flank of the structure have less mud loss, which is in accordance with the fracture distribution of the structure. This new method makes it possible to predict the mud loss flow rate before drilling, which is helpful in applying preventive measures during the drilling practice in steeply folded structures.

\section{ACKNOWLEDGMENTS}

This work is supported by the National Natural Science Foundation of China (No. 51104172, No. 51034007), the National Science and Technology Major Project of China (No. 2011ZX05026-001), "PCSIRT" Project (No. IRT1086) and the Natural Science Foundation of Shandong Province of China (No. ZR2010EL101).

\section{REFERENCES}

Anderson R.A., Ingram D.S., Zanier A.M. (1973) Determining Fracture Pressure Gradients from Well Logs, J. Petrol. Technol. 25, 11, 1259-1268, SPE Paper 4135, 10.2118/4135-PA.

Bell J.S., Aadnøy B.S. (1998) Classification of drilling induced fractures and their relationship to in-situ stress direction, $\log$ Analyst 39, 6, 216-223.

Chen M., Bai M. (1998) Modeling stress-dependent permeability for anisotropic fractured porous rocks, Int. J. Rock Mech. Min. Sci. 351, 8, 1113-1119.

Coblentz D.D., Sandiford M. (1994) Tectonic stresses in the African Plate: constraints on the ambient lithospheric stress state, Geology 22, 9, 831-834.

Constant David W., Bourgoyne Jr A.T. (1988) FractureGradient Prediction for Offshore Wells, SPE Drilling Eng. 3, 2, 136-140, SPE Paper 15105, 10.2118/15105-PA.

Dai J.S., Li L. (2000) Numerical simulation of tectonic stress field and fracture distribution of Mesozoic and Paleozoic Earthem in Chengdao area, J. University Petroleum 24, 1, 6-9.

Deng Pan, Wei Guo-qi, Yang Yong (2006) To establish and research three-dimentional geological and mathematical model for quantitative prediction of structure fracture, Natural Gas Geosci. 17, 4, 480-481.

Desroches J., Kurkjian A.L. (1999) Application of wireline stress measurement, SPE Paper 58086, 10.2118/58086-PA.

Draou A., Osisanya S.O. (2000) New Methods for Estimating of Formation Pressures and Fracture Gradients from Well Logs, SPE Annual Technical Conference and Exhibition, Dallas, Texas, 1-4 Oct., SPE paper 63263, 10.2118/63263-MS.
Du Q.C. (2004) Geological mechanics analysis and down hole complexity mechanics of the South Edge of Z hunger Basin, Southwest Petroleum University, Chengdu.

Gazaniol D., Forsans T., Boisson M.J.F., Piau J.-M. (1995) Wellbore failure mechanism in shales: prediction and prevention, J. Petrol. Technol. 47, 7, 589-595.

Ge H.K., Lin Y.S., Ma S.Z. (2001) Modification of Holbrook's Fracture Pressure Prediction Model, Petroleum Drilling Techniques 29, 3, 20-22.

Helio Santos, Placido J.C.R., Wolter C. (1999) Consequences and relevance of drilling vibration on wellbore stability, SPE/ IADC Drilling Conference, 9-11 March 1999, Amsterdam, Netherlands, SPE Paper 52820, 10.2118/52820-MS.

Hicks T.W., Pine R.J., Willis-Richards J., Xu S., Jupe A.J., Rodrigues N.E.V. (1996) A hydro-thermo-mechanical numerical model for HDR geothermal reservoir evaluation, Int. J. Rock Mech. Min. Sci. Geomech. Abstr. 33, 5, 499-511.

Holbrook P.W. (1989) A New Method for Predicting Fracture Propagation Pressure From MWD or Wireline Log Data, SPE Annual Technical Conference and Exhibition, San Antonio, Texas, 8-11 Oct., SPE Paper 19566, 10.2118/19566-MS.

Ji Z.Z., Dai J.S., Wang B.F. (2010a) Quantitative relationship between crustal stress and parameters of tectonic fracture, Acta Petrolei Sinica 31, 1, 68-72.

Ji Z.Z., Dai J.S., Wang B.F. (2010b) Multi-parameter quantitative calculation model for tectonic fracture, J. China University of Petroleum 34, 1, 24-28.

Kwon S., Mitra G. (2004) Three-dimensional finite-element modeling of a thin-skinned fold-thrust belt wedge: Provo salient, Sevier belt, Utah, Geology 32, 7, 561-564.

Lavrov A., Tronvoll J. (2004) Modeling mud loss in fractured formations, SPE Paper 88700.

Maerten L., Maerten F. (2006) Chronologic modeling of faulted and fractured reservoirs using geomechanically based restoration: Technique and industry applications, AAPG Bull. 90, 8, 1202-1226.

Murray G.H. Jr. (1968) Quantitative fracture Study - Sanish pool, McKenzie Co., North Dakota, AAPG Bull. 52, 1, 57-65.

Nikolaevskiy V.N., Economides M.J. (2000) The near-state of stress and induced rock damage, SPE International Symposium on Formation Damage Control, Lafayette, Louisiana, 23-24 Feb., SPE Paper 58716, 10.2118/58716-MS.

Prensky S. (1992) Borehole breakouts and in-situ rock stress-a review, The log analyst 33, 3, 304-312.

Quintana J.L., Ivan C.D., Blake L.D. (2001) Aphron-Base drilling Fluid: evolving technologies for lost circulation control, SPE Annual Technology Conference and Exhibition, New Orleans, Louisiana, USA, 30 Sept.-3 Oct., SPE Paper 71377.

Rocha L.A., Bourgoyne A.T. (1996) A New Simple Method To Estimate Fracture Pressure Gradient (includes associated paper 37685), SPE Drilling Completion 11, 3, 153-159, SPE Paper 28710, 10.2118/28710-PA.

Rocha L.A.S., Falcão J.L., Gonçalves C.J.C., Toledo C., Lobato K., Leal S., Lobato H. (2004) Fracture Pressure Gradient in Deepwater, IADC/SPE Asia Pacific Drilling Technology Conference and Exhibition, Kuala Lumpur, Malaysia, 13-15 Sept., SPE Paper 88011, 10.2118/88011-MS.

Sadiq T., Nashawi I.S. (2000) Using Neural Networks for Prediction of Formation Fracture Gradient, SPE/CIM International Conference on Horizontal Well Technology, Calgary, 
Alberta, Canada, 6-8 Nov., SPE Paper 65463, 10.2118/65463MS.

Settari A. (1988) A New General Model of Fluid Loss in Hydraulic Fracturing, SPE J. 25, 4, 491-501.

Song Huizhen, Zeng Hairong, Sun Junxiu, Lan Yingang, Huang Fuqiong (1999) Methods of reservoir tectonic fracture prediction and its application, Seismol. Geol. 21, 3, 205-213.

Vitthal S., McGowen J.M. (1996) Fracturing Fluid Leakoff Under Dynamic Conditions Part 2: Effect of Shear Rate, Permeability, and Pressure. SPE Annual Technical Conference and Exhibition, Denver, Colorado, 6-9 Oct., SPE Paper 36493, 10.2118/36493-MS.
Warpinski N.R. (1991) Hydraulic fracturing in tight, fissured media, J. Petroleum Technol. 43, 2, 146-151, 208-209.

Wei Jia, Tang Jie, Yue Chengqi, Wu Gangshan (2008) Study of 3-D geological structure model building, Geophys. Prospect. Petrol. 47, 4, 319-327.

Williams B.B. (1990) Fluid loss from hydraulically induced fractures, J. Pet. Technol. 22, 7, 882-888.

Xu T.T., Liu Y.J., Shen W. (1997) Leak protection and sealing technology, Petroleum Industry Press, Beijing, pp. 37-43.

Manuscript accepted in December 2012

Published online in September 2013 made or distributed for profit or commercial advantage and that copies bear this notice and the full citation on the first page. Copyrights for components of this work owned by others than IFP Energies nouvelles must be honored. Abstracting with credit is permitted. To copy otherwise, to republish, to post on servers, or to redistribute to lists, requires prior specific permission and/or a fee: Request permission from Information Mission, IFP Energiesnouvelles, fax.+3314752 70 96,or revueogst@ifpen.fr. 